\title{
MOBILE BANKING ADOPTION IN INDIA: DECOMPOSED TPB APPROACH
}

\author{
Anubhuti Dwivedi \\ Professor and Dean \\ Asian Business School, Noida, India \\ anubhutidwivedi@gmail.com \\ Maroof Ahmad Mir \\ Associate Professor \\ Asian Business School, Noida, India \\ mirmaroofahmad@gmail.com
}

\begin{abstract}
Technological innovations have significant impact in human life. The quick expansion of information technology has been adopted into the lives of millions of people. Rapid progress and advancement in technology have brought about significant alteration in the global business environment. Information technology developments in the banking sector have sped up communication and transactions. It is vital to extend this new banking feature to clients for maximizing the advantages for both clients and service providers and hence the purpose of this study is to explore the factors that influence the intention of consumers to use mobile banking so that it can be made popular among banking customers in India.
\end{abstract}

The research framework applied in this study is based on the Theory of Planned Behaviour (TPB) (Ajzen 1985) decomposed using factors given in the diffusion of innovations theory (Rogers 1983). This Decomposed Theory of Planned Behaviour has been adapted from Taylor \& Todd (1995). Multiple linear regression analysis was used to test the hypotheses formed for the study. The independent variables (attitude, subjective norms, and behavioural controls) were regressed on "intention to adopt" as the dependent variable. To analyse for convergent and discriminant validity of the constructs, factor analysis was used.

The results exhibit that attitude and perceived behavioural control factors play a significant role in influencing intentions to adopt mobile banking but social influence is not found significant. In particular, perceptions of relative advantage, compatibility, trialability and risk were found significant in influencing intentions to adopt mobile banking services. Self-efficacy in using mobile banking services and technology facilitating conditions were also found to influence intentions.

Keywords: Mobile banking, adoption intention, Theory of Planned Behaviour (TPB)

\section{Introduction}

To sustain business competitiveness, more and more banks have transformed from their traditional banking mode to the internet banking and mobile banking mode. For achieving different competitive advantages, which include cost 
containment, performance improvement, market penetration, and product transformation, banks are finding ways to utilize mobile technologies. An important requisite for attaining success in bringing in more customers towards mobile banking service is to understand what factors will impact the decisions of customers in adopting the service.

The objective of this study is to identify and analyse the role of attitudinal factors, social norms and behavioural control factors in influencing intentions to adopt mobile banking services in India. A framework based on the Theory of Planned Behaviour (Ajzen 1985) and Diffusion of Innovations Theory (Rogers 1983) is used to derive the factors. The study contributes to theory and practices both by helping in understanding the theoretical constructs influencing the adoption of mobile banking and practically assisting the banks in understanding major factors that influence the customer intentions of adopting mobile banking services.

The structure of the paper is as follows: it describes the research framework followed by the research method, it then discusses the online questionnaire that was used to conduct the survey and later the findings are presented. The paper concludes with a discussion on the research implications of the study.

\section{Research framework}

The research framework applied in this study is based on the theory of planned behaviour (TPB) (Ajzen 1985) decomposed using factors given in the Diffusion of Innovations Theory (Rogers 1983) adapted from Taylor \& Todd (1995). The decomposed TPB model further breaks the attitudinal factors using constructs from the innovations theory and also offers a deeper insight into subjective norms and perceived behavioural control by decomposing them further into more specific parameters. It provides a comprehensive explanation of the influence which an individual customer's attitude, subjective norms and perceived behavioural control can exert on his or her intention to use mobile banking services.

The framework postulates that a person's intention to adopt mobile banking can be explained by three factors: First, attitude defined as an individual's perception towards mobile banking; second, subjective norms, which describe the social influence that may affect a person's intention to use mobile banking; and third, perceived behavioural control, which describes the beliefs about having the necessary resources and opportunities to adopt banking. In the context of the framework, intention to adopt mobile banking services is thus the dependent variable, while the independent variables comprise of attitude, subjective norms, and perceived behavioural control.

\section{Attitude}

Attitude is defined as an individual's positive or negative feelings (evaluative effect) about performing target behaviour (Fishbein and Ajzen 1975). It is related to behavioural intention because people form intentions to perform behaviours toward which they have positive affect (Khan and Rizvi 2012). Taylor and Todd (1995) suggest compatibility, complexity, observability, relative advantage and trialability as the five perceived attributes, proposed originally by Rogers 1983 in the diffusion of innovation theory, to measure the different dimensions of attitudinal belief toward an innovation. Observability is considered irrelevant in this study because an essential feature of mobile banking is privacy. Diffusion of Innovation Theory has been recently used to explain the adoption of mobile banking by Mullan et al. (2017)

Relative Advantage: Tornatzky and Klein (1982) found relative advantage to be an important factor in determining adoption of new innovations. Rogers 1983 found positive relationship between perceived relative advantage of an 
innovation and its rate of adoption. Likewise, as mobile banking services allow customers to access their banking accounts from any location and at any time, it provides tremendous advantage and convenience to users which leads to better control over managing customer's finances. In view of the advantages that mobile banking services offer, it would thus be expected that individuals who perceive mobile banking as advantageous would also be likely to adopt the service. This leads to the hypothesis:

H1A: Perceived relative advantage of using mobile banking services is positively related to the adoption of internet banking.

Compatibility: It is expected that the more the individual uses the mobile banking, and the more he or she perceives the mobile banking as compatible with his or her lifestyle, which in-turn leads to more chances of adopting mobile banking. Thus, the hypothesis is:

$\mathrm{H} 1 \mathrm{~B}$ : Experience with using the mobile is positively related to the adoption of mobile banking.

In terms of compatibility mobile banking can be a preferred tool for customers to effortlessly manage their multiple accounts with more ease and control. As there are more financial products and services, it is expected that individuals who may have many financial accounts and who subscribe to many banking services and transact more frequently will be more inclined to adopt mobile banking. This leads to the following hypothesis:

H1C: The magnitude and frequency of use of banking products and services is positively related to the adoption of mobile banking.

Complexity: The complexity of use of a technology entails greater effort on the part of the user and thus the techniques which are less complex are more likely to be adopted. If the potential customers feel that mobile banking services are less complex to use, they would be likely to use mobile banking more readily. This leads to the hypothesis:

H1D: Perceived complexity of using mobile banking is negatively related to the adoption of mobile banking.

Trialability: As discussed in Rogers (1983) the potential innovation adopters who get an opportunity to try an innovation and experiment with it are more likely to adopt the same as the trial makes them comfortable with the innovation. Thus, if customers are given the opportunity to try the innovation, certain fears of the unknown may be minimized. This is especially true when customers find that mistakes could be rectified, thus providing a predictable situation. This leads to the hypothesis:

H1E: Trialability of mobile banking is positively related to the adoption of mobile banking.

Risk: Bauer (1960), Webster (1969), and Ostlund (1974) introduced risk as an additional dimension in diffusion and adoption. Several studies have pointed that the most common hindrance in adoption of electronic commerce is the perception about lack of security and privacy over the Internet (Bhimani 1996; Cockburn and Wilson 1996; Quelch and Klein 1996). Thus, it is expected that only individuals who perceive using mobile banking as a low risk phenomenon would be inclined to adopt it. This leads to the hypothesis:

H1F: Perceived risk of using mobile banking is negatively related to the adoption of mobile banking.

\section{Subjective Norms}

Subjective norms refer to an individual's perception about what one's reference group comprising of people important to 
oneself think if one should or should not perform a particular behaviour. (Fishbein and Ajzen 1975). It is considered to influence intention because people usually behave according to their perception of how others think they should behave. Subjective norms have been found to be significant in the early stages of implementation of an innovation as by that time the users do not have direct experience of the innovation from which they can develop attitudes (Hartwick and Barki 1994; Taylor and Todd 1995). Though it is difficult to predict the influence of the consumer relevant referent groups on their intention to adopt mobile banking, but based on prior literature, it is expected that the influence of these groups as a whole will be significantly related to the individual's intention to adopt mobile banking. Therefore, the following hypothesis needs to be investigated.

H2: The beliefs related to subjective norms have a significant influence on an individual's intention to adopt mobile banking.

\section{Perceived Behavioural Control}

Perceived behavioural control refers to the factors that may impede the performance of the behaviour. This definition encompasses two components. The first component is self-efficacy and is defined as an individual's self-confidence in his or her ability to perform a behaviour (Bandura 1977, 1982; Rajmohan et.al. 2010 and Chaouali et.al. 2017). The second component is "facilitating conditions" and it reflects the availability of resources needed to engage in the behaviour (Triandis 1979).

Thus, an individual confident in having the skills in using the mobile and the mobile is more inclined to adopt mobile banking as the individual would be comfortable in using the innovation. This leads to the hypothesis:

H3A: Self-efficacy towards using mobile banking is positively related to the adoption of mobile banking.

The second component in the behavioural control construct is, "facilitating conditions," which refer to the easy access of technology and resources required for using mobile banking. Consumers would be expected to be more inclined to adopt mobile banking if they have resources to have access to mobile phone and high speed mobile connectivity is easily available. This leads to the following hypothesis:

H3B: Extent of perceived technological and resource support for mobile banking is positively related to the adoption of mobile banking.

\section{Research design}

This study adopts an online questionnaire survey circulated through a commercial online survey platform to reach the desired sample of users from across the country. Purposive sampling was used by specifying the requirements for the sample i.e. the respondents should be from each region of India in proportion to the population of the respective region, they should be above 18 years of age, holding a bank account and using mobile internet services. Out of the registered survey panellists on the panel of the commercial survey firm, respondents fulfilling these criteria were stratified in terms of northern, southern, central, western and eastern regions of India and 500 total sample units were then random. ly selected proportionate to population of the region from each region to have a representative sample with a reasonable sample size after accounting for the response rate. As this is an empirical study for testing the factors based on Theory of Planned Behaviour and 
Diffusion of Innovation Theory affecting the mobile banking adoption in India, it was considered more appropriate to initially survey the sample of mobile internet users to test the hypotheses. Hence, the findings of this study can only apply to mobile internet users in India rather than the general population.

Question items used, in most cases, were adapted from prior literature using a 7-point Likert scale with anchors ranging from strongly agree to strongly disagree. To measure influence on decision to adopt mobile banking by their friends, family, and colleagues/peers the respondents were asked to indicate their preference in terms of agreement or disagreement. To measure self-efficacy towards usage of Internet banking systems, the instrument developed by Compeau and Higgins (1995) was adapted in the context of Internet banking. Five different usage situations were used to indicate the respondent's confidence in using mobile banking. The items used to measure Technology support for Internet banking were constructed based on relevant literature.
Two items were used to assess respondents' intentions to adopt mobile banking (Tan and Teo 2000). The first item asks respondents the extent to which they would be interested in using mobile banking if it were available to them. The other item was used to know the likelihood of respondent to adopt mobile banking in the next 6,12 , and 18 months. Babbie (1990) suggests weighting the responses in order to derive a value representative of such a scale. With this in mind, a numerical figure for the second item is computed as follows: the time periods of 6,12 , and 18 months are assigned the weights of $3 / 6,2 / 6$ and $1 / 6$ respectively. Value between 1 and 7 for the second item to represents the respondent's intention to adopt mobile banking was found by taking the summation of the responses multiplied by their respective weights.

Respondents participated through extensive personalized email invitations. Of the 500 personalized e-mails sent out, 110 were returned by the servers. Therefore, only 390 personalized e-mails were effectively sent. A total of 390 sets were collected. Out of this lot, 54 were found to have missing data. Therefore, data were collected from a total of 336 sets.

TABLE 1. DEMOGRAPHIC CHARACTERISTICS OF RESPONDENTS $(\mathrm{N}=336)$

\begin{tabular}{|lccc|}
\hline Demographic characteristics & Frequency & Percent(\%) & Cumulative (\%) \\
\hline Gender & & & \\
\hline Male & 187 & 55.7 & 55.7 \\
\hline Female & 149 & 44.3 & 100 \\
\hline Age & & & \\
\hline$<25$ years & 78 & 23.2 & 23.2 \\
\hline $25-45$ years & 147 & 43.8 & 67.0 \\
\hline$>45$ year & 111 & 33.0 & 100 \\
\hline
\end{tabular}


Reliability and Validity Assessment As a standard procedure the research instrument was tested for its reliability, by computing Cronbach's coefficient alpha, and for the construct Validity.

Table 2 shows the Cronbach's alpha for the constructs in the research framework. A minimum alpha value of 0.6 is suggested for early stage of research by Nunnally (1967). As the Cronbach's alphas range from 0.69 to 0.94 , the constructs are deemed to have adequate reliability for the next stage of validity analysis.
To analyze for convergent and discriminant validity of the constructs, factor analysis was used. The Kaiser-Meyer-Olkin measure of sampling adequacy (MSA) was first computed to determine the suitability of using factor analysis. For this study, the MSA was found to be 0.812 . Thus, it was deemed appropriate to apply factor analysis. Construct validity was evaluated by convergent and discriminant validity.

TABLE 2. SUMMARY OF RELIABILITY AND VALIDITY ANALYSIS OF CONSTRUCTS

\begin{tabular}{|c|c|c|c|c|c|}
\hline Construct & Variables & Items & $\begin{array}{l}\text { Cronbach's } \\
\text { alpha }\end{array}$ & $\begin{array}{l}\text { Factor } \\
\text { Loadings }\end{array}$ & $\begin{array}{l}\text { Average } \\
\text { Variance } \\
\text { Extracted }\end{array}$ \\
\hline ATTITUDE & $\begin{array}{l}\text { Relative Advantage } \\
\text { Compatibility with Mobile and } \\
\text { Mobile Applications } \\
\text { Compatibility with Banking Needs } \\
\text { Complexity }\end{array}$ & $\begin{array}{l}\text { RELADV1 } \\
\text { RELADV2 } \\
\text { RELADV3 } \\
\text { RELADV4 } \\
\text { RELADV5 } \\
\\
\text { MOBUSE1 } \\
\text { MOBUSE2 } \\
\text { MOBUSE3 } \\
\text { MOBUSE4 } \\
\text { APPSKILL } \\
1 \\
\text { APPSKILL } \\
2 \\
\text { APPSKILL } \\
3 \\
\text { APPSKILL } \\
4 \\
\end{array}$ & . & $\begin{array}{l}0.813 \\
0.856 \\
0.739 \\
0.847 \\
0.819 \\
\\
\\
\\
0.631 \\
0.794 \\
0.726 \\
0.712 \\
0.743 \\
0.812 \\
0.841 \\
0.758 \\
\\
\\
0.806 \\
0.794 \\
0.832 \\
\\
0.742 \\
0.713 \\
0.806\end{array}$ & 0.64 \\
\hline
\end{tabular}


TABLE 3. SHARED VARIANCES

\begin{tabular}{|c|c|c|c|c|c|c|c|c|}
\hline Construct & RELAD & COMPI & OMPI & OMPL & TRIAL & RISK & SELFEFF & TECHSUP \\
\hline RELADV & 0.64 & & & & & & & \\
\hline COMPINT & 0.12 & 0.52 & & & & & & \\
\hline COMPBN & 0.06 & 0.16 & 0.59 & & & & & \\
\hline COMPLX & 0.05 & 0.03 & 0.13 & 0.51 & & & & \\
\hline TRIAL & 0.11 & 0.06 & 0.07 & 0.06 & 0.78 & & & \\
\hline RISK & 0.21 & 0.14 & 0.05 & 0.02 & 0.24 & 0.71 & & \\
\hline SELFEFF & 0.16 & 0.05 & 0.01 & 0.06 & 0.26 & 0.41 & 0.66 & \\
\hline TECHSUP & 0.17 & 0.03 & 0.01 & 0.04 & 0.16 & 0.38 & 0.23 & 0.76 \\
\hline
\end{tabular}

Prior to regression analysis, the data were tested for heteroskedasticity and multicollinearity. Heteroskedasticity refers to the occurrence of unequal variances while multicollinearity refers to high correlations among the independent variables.

Few assumptions for regression analyses are violated due to occurrences of these two effects. It is important to test for heteroskedasticity as different sample populations that make up the pool of respondents may have different variances. To test for heteroskedasticity, Spearman's rank correlation was used.

Gujarati 1995 suggests that for heteroskedasticity to exist, the correlation coefficient should be significant (i.e., $p<$ 0.05). Since results indicate that the coefficient is not significant (Spearman's correlation coefficient $=-0.013, \mathrm{t}=0.513$, $\mathrm{p}>0.05$ ), there is thus no heteroskedasticity that may cause misleading conclusions in the hypothesis testing. To test for multicollinearity, the variance inflation factor (VIF) for each independent variable was computed.

All of the VIF values are well below 10, ranging from 1.081 to 3.016 . Therefore, the problem of multicollinearity does not exist.

\section{Findings and analysis}

Nine hypotheses were formulated for the study. Multiple linear regression analysis was used to test the hypotheses. The independent variables (attitude, subjective norms, and behavioural controls) were regressed on "intention to adopt" as the dependent variable. Table 4 presents the results of the regression. Table 3 shows that all of the hypotheses, with the exception of H1D (complexity) and H2 (subjective norms) are supported.

The support for H1A (relative advantage) is expected as the past literature has consistently shown that perceived relative advantage has a significant and positive influence on the adoption of new innovations (Holak and Lehmann 1990; Tornatzky and Klein 1982).

The support for H1B (mobile Banking experience) is consistent with Rogers' suggestion that compatibility of an innovation with a previously introduced idea can influence the adoption of the innovation. Further, Hirschman (1980) has suggested that prior experience with a product class (the mobile and mobile applications in this case) may lead to greater acceptability of new products (mobile banking in this case), hence increasing the likelihood that they will be adopted. 
TABLE 4. MULTIPLE REGRESSION RESULTS

\begin{tabular}{|c|c|l|c|c|}
\hline Factor & Hypothesis & \multicolumn{1}{|c|}{ Variable } & Beta & p- value \\
\hline \multirow{4}{*}{\begin{tabular}{c} 
Attitude \\
\cline { 2 - 5 }
\end{tabular}} & H1A & Relative Advantage & 0.213 & 0.004 \\
\cline { 2 - 5 } & H1B & Internet Experience & 0.102 & 0.016 \\
\cline { 2 - 5 } & H1D & Banking Needs & 0.054 & 0.008 \\
\cline { 2 - 5 } & H1F & Trialability & -0.017 & 0.127 \\
\hline \multirow{2}{*}{$\begin{array}{c}\text { Subjective } \\
\text { Norms }\end{array}$} & H2 & Subjective Norms & 0.236 & 0.005 \\
\hline \multirow{2}{*}{$\begin{array}{c}\text { Perceived } \\
\text { Behavioural } \\
\text { Control }\end{array}$} & H3A & Self-Efficacy & 0.096 & 0.0229 \\
\cline { 2 - 5 } & H3B & Technology Support & 0.135 & 0.000 \\
\hline
\end{tabular}

The support for H1C (banking needs) is also consistent with Roger's suggestion that an innovation is more likely to be adopted if it meets a felt need. Therefore, it is likely that Mobile banking users who have many bank accounts and who subscribe to many banking services and have to do more frequent banking transactions would look forward to more convenient and easily accessible delivery channels such as mobile banking and therefore will have more chances of adopting them.

Also, the support for H1E (trialability) is consistent with Rogers' argument that potential adopters who are able to experiment with an innovation will be able to give meaning to it and feel more comfortable with it and thus have higher chances to adopt such innovations.

The support for H1F (risk) reflects similar arguments in the Internet banking literature (Bhimani 1996; Cockburn and Wilson 1996; Lee 1996; Quelch and Klein 1996), which states that the perceived security and privacy risk associated with banking on the Internet is a major impediment to the adoption of Internet banking.

As expected, H3A (self-efficacy) is supported. Therefore, mobile users with confidence in their abilities to use mobile banking would prefer adopting such services. This is consistent with the findings of previous studies (Burkhardt and Brass 1980; Hill et al. 1986), which found that self-efficacy has a significant influence on intentions to adopt new innovations.

H3B (perceived technology support) for mobile banking is also found to have a significant influence on intentions to adopt mobile banking services as expected because the required technology support through mobile facilities along with hardware support is essential for consumers to be able to adopt mobile banking.

Conversely, the lack of support for H1D (complexity) is in contrast with certain previous findings (Cooper and Zmud 1990; Dickerson and Gentry 1983; Moore 1987), which indicated that the complex innova- 
tions require greater skills and efforts and thus such innovation is unlikely to be adopted. However, Moore and Benbasat (1991) have suggested that perceived complexity of using an innovation begins to play a more instrumental role only after one has started hands-on trials and/or use of the technology. Since mobile banking in India is still in the early stages of implementation, not many mobile users have tried it to be able to develop a perception about its complexity. As a result, their perceived complexity of using such services may not be significant in influencing their intentions to adopt mobile banking.

The results also show that the influence of the mobile banking user's consumer relevant groups (H2) on his or her adoption is not significant. This result is in contrast with the results reported by Hartwick and Barki and by Taylor and Todd (1995), who found subjective norms to be important in affecting adoption because of limited direct experience in the early stages of introducing an innovation. A possible explanation for the lack of support for this hypothesis is that the easy access to information about the mobile banking has made potential adopters less reliant on the information provided by their referent groups and also because the referent group itself does not comprise of a significant proportion of mobile banking users.

\section{Conclusion and implications}

The findings show that intention to adopt mobile banking services can be predicted by attitudinal and perceived behavioural control factors, but not by subjective norms. The attitudinal factors that are significant include relative advantage; compatibility with respondent's lifestyle, experience, and needs; trialability; and risk. An insignificant negative relationship is found between perceived complexi- ty and adoption intentions. Subjective norms, in the form of the influence of the mobile banking user's consumer-relevant groups, are found to have no significant relationship with intention to adopt mobile banking. With regard to perceived behavioural control, both self-efficacy and technology support are found to be important.

The findings generated from this study have important implications for both research and the banking community. In terms of research, this study provides further evidence on the appropriateness of using Roger's innovation attributes to measure the different dimensions of attitude toward mobile banking. Out of the four innovation attributes measured, only the relationship between perceived complexity of using mobile banking services and intentions to adopt such services was not supported. This discrepancy could be due to the inherent characteristics of the sample of Indian mobile banking users rather than the inappropriateness of the measure.

The results from this study have also shown that there are other factors besides attitudinal ones that can help us to better understand the adoption intentions of mobile banking. Two additional influencing factors (subjective norms and perceived behavioural control) proposed by Ajzen in the Theory of Planned Behaviour, were included in this study. Although subjective norms were not found to significantly influence adoption intentions, perceived behavioural control dimensions were found to have significant influences.

The findings of this study also hold important practical implications for banks that are currently offering mobile banking services as well as banks that are 
planning to offer such services. For example, in promoting mobile banking, since potential adopters are found to rely more on their own efforts to search for information rather than rely on referent groups, banks should launch awareness campaigns for the potential customers. Issues such as fears of privacy and security risks together with relative advantages of using mobile banking services could be highlighted to educate potential customers.

There is further scope of detailed research into the adoption of mobile banking services. Future study should focus on the users who are yet to adopt the mobile banking service to identify the gaps. Furthermore, as mobile banking services are still relatively less popular in India and getting the data of mobile banking users from banks was not possible, this study has been unable to measure the actual usage behaviour of such services, which was suggested by the Theory of Planned Behaviour (Ajzen 1985). Future studies should incorporate this measure once the number of mobile banking customers has reached a critical mass.

\section{References}

Ajzen, I. (1985). From intentions to actions: A Theory of Planned Behaviour. Action control: from cognition to behaviour, J. Kuhl and J. Beckmann (eds.), New York: Springer-Verlag, pp.11-39.

Babbie, E. R. (1990). Survey research methods, Wadsworth Pub. Co Belmont, Calif, 3(9).

Bandura, A. (1977). Self-Efficacy: toward a unifying theory of behavioural change. Psychological Review (84), pp. 191-215.

Bandura, A. (1982). Self-efficacy mechanism in human agency. American
Psychologist (37:2), pp. 122-147.

Bauer, R. A. (1960). Consumer behaviour as risk taking. Chicago, IL, 384-398.

Bhimani, A. (1996). Securing the commercial internet. Communications of the ACM (39:6), pp. 29-35.

Booz-Allen \& Hamilton. (1997). Booz-Allen's worldwide survey revealed a huge perception gap between Japanese and American/European banks regarding internet banking. Retrieved from http://www.bah.com/press/jbankstudy.html

Chaouali, W., Souiden, N., \& Ladhari, R. (2017). Explaining adoption of mobile banking with the theory of trying, general self-confidence, and cynicism. Journal of Retailing and Consumer Services, 35, 57-67.

Chau, PYK \& Lai, VSK (2003). An empirical investigation of the determinants of user acceptance of internet banking. Journal of Organizational Computing and Electronic Commerce, 13:2, pp. 123-145.

Cockburn, C., \& Wilson, T. D. (1996). Business use of the World Wide Web. International Journal of Information Management (16:2), pp. 83-102.

Compeau, D. R., \& Higgins, C. A. (1995). Computer self-efficacy: Development of a measure and initial test. MIS quarterly, 189-211.

Cooper, R. B., \& Zmud, R. W. (1990). Information technology implementation research: A technological diffusion approach. Management science, 36(2), 123-139.

Dee Dickerson, M., \& Gentry, J. W. (1983). Characteristics of adopters and non-adop- 
ters of home computers. Journal of Consumer research, 10(2), 225-235.

Fishbein, M., and Ajzen, I. (1975). Belief, attitude, intention and behaviour: an introduction to theory and research, reading, MA: Addison-Wesley.

Gujarati, D. N. (1995). Basic Econometrics, New York: McGraw-Hill.

Hartwick, J., \& Barki, H. (1994). Explaining the role of user participation in information system use. Management Science, 40(4), 440-465.

Hirschman, E. C. (1980). Innovativeness, novelty seeking, and consumer creativity. Journal of Consumer Research, 7(3), 283-295.

Holak, S. L., \& Lehmann, D. R. (1990). Purchase intentions and the dimensions of innovation: An exploratory model. Journal of Product Innovation Management: An International Publication of the Product Development \& Management Association, 7(1), 59-73.

Khan, S., \& Rizvi, A. H. (2012). Factors influencing the consumers' intention to shop online. Skyline Business Journal, $7(1)$.

Liao, S., Shao, Y. P., Wang, H., \& Chen, A. (1999). The adoption of virtual banking: an empirical study. International Journal of Information Management (19:1), pp. 63-74.

Moore, G. (1987). End user computing and office automation: a diffusion of innovations perspective. INFOR: Information Systems and Operational Research, 25(3), 214-235.

Moore, G. C., \& Benbasat, I. (1991). Devel- opment of an instrument to measure the perceptions of adopting an information technology innovation. Information Systems Research, 2(3), 192-222.

Mullan, J., Bradley, L., \& Loane, S. (2017). Bank adoption of mobile banking: stakeholder perspective. International Journal of Bank Marketing, 35(7), 1154-1174.

Nunnally, J. C (1967). Psychometric theory. New York, NY, US: McGraw-Hill.

Ostlund, L. E. (1974). Perceived innovation attributes as predictors of innovativeness. Journal of Consumer Research, 1(2), 23-29.

Quelch, J. A., \& Klein, L. R. (1996). The internet and international marketing. MIT Sloan Management Review, 37(3), 60 .

Rajmohan, P., Sabha, N., \& Rushdi, S. (2010). B2C e-Commerce adoption possibilities in UAE: An empirical study on E-Readiness of Consumers. Skyline Business Journal, 6(1).

Rogers, E.M. (2003). Diffusion of innovations. New York: Free Press.

Tan, M., \& Teo, T. S. (2000). Factors influencing the adoption of Internet banking. Journal of the Association for Information Systems, 1(1), 5.

Taylor, S., \& Todd, P. A. (1995). Understanding information technology usage: A test of competing models. Information Systems Research, 6(2), 144-176.

Tornatzky, L. G., \& Klein, K. J. (1982). Innovation characteristics and innovation adoption-implementation: A meta-analysis of findings. IEEE Transactions on 
Engineering Management, (1), 28-45.

Triandis, H. C. (1979). Values, attitudes and interpersonal behaviour in Nebraska Symposium on motivation, beliefs, attitudes and values, Lincoln, NE: University of Nebraska Press, 195-259.

Webster, F. E., Jr. (1969). New product adoption in industrial markets: a framework for analysis, Journal of Marketing, 33(3), 35-39.

How to cite this article: Dwivedi, A. \& Mir, M. A. (2019). Mobile banking adoption in India: Decomposed TPB approach. Skyline Business Journal, 15(2), 1-12.

https://doi.org/10.37383/SBJ14021901 